\title{
3-D Printing of Open Source Appropriate Technologies for Self-Directed Sustainable Development
}

\author{
J. M Pearce (Corresponding author) \\ Queen's Applied Sustainability Research Group \\ Department of Mechanical and Materials Engineering \\ School of Environmental Studies, Queen's University \\ 60 Union St., Kingston, ON K7L 3N6, Canada \\ Tel: 1-613-533-3369 E-mail: pearce@me.queensu.ca \\ C. Morris Blair \\ Queen's Applied Sustainability Research Group \\ Department of Engineering Physics, Queen's University \\ 60 Union St., Kingston, ON K7L 3N6, Canada \\ K. J. Laciak \\ Queen's Applied Sustainability Research Group \\ Department of Mathematics and Engineering, Queen's University \\ 60 Union St., Kingston, ON K7L 3N6, Canada \\ R. Andrews \& A. Nosrat \\ Queen's Applied Sustainability Research Group \\ Department of Mechanical and Materials Engineering, Queen's University \\ 60 Union St., Kingston, ON K7L 3N6, Canada \\ I. Zelenika-Zovko \\ Queen's Applied Sustainability Research Group \\ School of Environmental Studies, Queen's University \\ 60 Union St., Kingston, ON K7L 3N6, Canada
}

This research was funded by the Natural Sciences and Engineering Research Council of Canada.

\begin{abstract}
The technological evolution of the 3-D printer, widespread internet access and inexpensive computing has made a new means of open design capable of accelerating self-directed sustainable development. This study critically examines how open source 3-D printers, such as the RepRap and Fab@home, enable the use of designs in the public domain to fabricate open source appropriate technology (OSAT), which are easily and economically made from readily available resources by local communities to meet their needs. The current capabilities of open source 3-D printers is reviewed and a new classification scheme is proposed for OSATs that are technically feasible and economically viable for production. Then, a methodology for quantifying the properties of printed parts and a research trajectory is outlined to extend the existing technology to provide complete village-level fabrication of OSATs. Finally, conclusions are drawn on the potential for open source 3-D printers to assist in driving sustainable development.
\end{abstract}

Keywords: Appropriate technology, Local manufacturing, Open design, Open source, Open source appropriate technology, Peer to peer production, Self-reliance, Sustainable development

\section{Introduction}

Appropriate technology (AT), which can be defined as those technologies that are easily and economically used from readily available resources by local communities to meet their needs, must comply with environmental, cultural, economic, and educational resource constraints of the local community (Hazeltine \& Bull, 2003; Buitenhuis, Zelenika, \& Pearce, 2010). AT was first popularized by E.F. Schumacker in his classic text Small is beautiful: a study of economics as if people mattered (1973). Development using appropriate technologies had 
some traction early in the 1970s because of the massive poverty in the developing world and the failure of traditional development models, but was largely buried by methods that favored the extraction of wealth from populations geographically located in regions of environmental abundance and natural resources (Pursell, 1993). Of the methods of sustainable development that have been most successful at enabling the impoverished to pull themselves out of poverty are those that favor egalitarian, local, small scale, people centered, bottom-up, peer-to-peer methodologies, which directly supports AT paradigms (Pollock, 2009). Unfortunately, despite successes of extracting people in abject poverty numbering in the millions (Pollock, 2009), AT has not yet successfully scaled throughout the world as is witnessed by the number of people still mired in poverty (Ferreira \& Ravallion, 2008). One cause of this is that when appropriate solutions are found, they are not well-documented or shared and there is little access to the information for other communities that could put it to use (Kanter, et al., 2009). In order to prevent reinventing the proverbial wheel, there is clearly a need for a new way for designing and disseminating AT so marginalized communities can access it (Buitenhuis, Zelenika, \& Pearce, 2010).

As internet access spreads to even to the world's least developed countries, the commons-based open design or 'open source' method has promise to accelerate development of AT (Pearce \& Mushtaq, 2009). Open source appropriate technology (OSAT) has the ability to harness the power of distributed peer review, source transparency, and the gift culture from the open source movement/academia and the contextual development capacity of ATs (Pearce, 2009; Pearce \& Mushtaq, 2009). In parallel to the open source movement in software, OSAT allows technology users to be developers simultaneously and share the open "source code" of their physical AT designs. Thus, rather than programming code, the "source code" for AT are material lists, directions, specifications, designs, 3-D CAD, techniques, and scientific theories needed to build, operate, and maintain AT. Users are free to use and modify the "source code" from any shared AT and, via the internet, can engage in a massive parallel world-wide peer review process to determine the best practices and solutions. One of the key impediments to the more rapid development of OSAT is the lack of means of production of open source technologies beyond a specific technical complexity.

This barrier is being challenged by the rise of the open source 3-D printer, affordable versions of which are capable of replicating any three dimensional object that can fit into a shoe box in a number of polymers and resins. The most striking of these is the RepRap, so named because it can fabricate roughly $48 \%$ (excluding nuts, washers, and bolts) of its own components and is thus on the path of becoming a self-replicating rapid prototyper. These devices, however, are all at the early stages of development. This paper critically examines the opportunity that open source 3-D printers, such as the RepRap, provide for OSAT development by first providing a preliminary review of the technology's current capabilities. Then a classification scheme is developed to group appropriate technologies by technical feasibility and economic viability for production from the existing printers and then extended over technically viable near term developments in open source 3-D printers. Finally a research trajectory will be outlined to extend the existing technology to provide the based for a complete village level fabrication for OSAT. These results are discussed and conclusions are drawn on the potential for open source 3-D printers to assist in sustainable development.

\section{Open Source 3-D Printing}

Traditionally, 3-D printing has been used for rapid prototyping, where good tolerances, durability and fast print times dominate the user requirements (Cheah, 1997; $\mathrm{Li}, 1998$ ). Traditional manufacturing techniques for consumer and industrial products such as injection molding and CNC milling typically produce a greater accuracy than 3-D printing, at the expense of increased production time and cost for complex objects (Karunakaran, et al., 2010; Rao \& Padmanabhan, 2007). For this reason, commercial rapid prototyping machines are used in many industries to make custom parts for design-stage products and are able to perform operations such as printing a working ball bearing using overhangs and two material deposition methods. Recently, the development of open-source rapid prototypers, such as the RepRap and the Fab@Home, have made rapid prototyping inexpensive enough to be accessible to home users and potentially useful for OSAT. Commercial printers excel at rapidly producing high-tolerance representations of complex parts; however, they are far more expensive $(\$ 5000-\$ 200,000)$ than the $\sim \$ 1,000$ open source rapid prototypers. Also as proprietary rapid prototypers generally have proprietary feedstocks, they are also extremely expensive $\left(\$ 1 / \mathrm{in}^{3}\right.$ to $\left.\$ 4 / \mathrm{in}^{3}\right)$, while ABS plastic, often used for the RepRap, is strikingly less expensive at $\$ 0.032 / \mathrm{in}^{3}$ (Harper, 2001).

Although there are many types of small scale 3-D printers, both the RepRap and the Fab@home are open-source projects, which were started at universities and have a large open source community supporting their development (Malone \& Lipson, 2007; Sells, et al., 2009). Both projects are focused on being affordable to households and thus potentially inexpensive enough to be justified for use in OSAT. A version based off of the first generation RepRap has already been commercialized by Bits from Bytes and sells for $<\$ 1,000$. Both the RepRap and the Fab@home have full instructions online as part of their respective wikis (www.reprap.org and www.fabathome.org/wiki) and sources to obtain their plastic parts. The properties of the two types of open source rapid prototypers are summarized in Table 1 and the properties of the most common open-source printable materials are summarized in Table 2. 


\subsection{RepRap}

RepRap was started by Adrian Bowyer at the University of Bath and his team has since designed and built two printers, one being the first generation called Darwin and a second generation called Mendel. All of the Mendel machine's plastic parts were printed on the Darwin prototyper while attempting to fix Darwin's problems. These improvements included making the printing area bigger, improved z-axis constraints, better axis efficiency, simpler assembly, the ability to allow extruder head change, and lighter weight (RepRap, 2010). The most important goal to this community is self replication of the machine (Sells, et al., 2009) and currently Mendel can print $6.83 \%$ of its parts by number (counting each bolt, washer, and nut as separate piece), but $48 \%$ excluding nuts, bolts, and washers (RepRap, 2010). The remainder of the machine can be built using locally sourced materials and electronic equipment that can be bought or put together (Sells et al., 2009). The RepRap can currently print with ABS, polycaprolactone, polyactic acid, and HDPE, which all cost between \$7-14/lb (Sells, et al., 2009; RepRap 2010). The extruder intakes a filament of the working material, heats it, and extrudes it through a nozzle. The printer uses a three coordinate system, where each axis involves a stepper motor that makes the axis move and a limit switch, which prevents further movement along the axis. The printing process is a sequential layer deposition where the extruder nozzle deposits a 2-D layer of the working material, then the Z (vertical) axis will lower, and the extruder will deposit another layer on top of the first. In this way it can build three dimensional models from a series of two dimensional layers. The printer can handle up to $45^{\circ}$ overhang, but new methods are being developed to allow full overhangs including printable supports (Sells, et al., 2009). The maximum size of a printed object is $1,110 \mathrm{~cm}^{3}$ (RepRap, 2010). These physical characteristics limit the scope of OSATs that can be currently be printed and will be discussed in detail in Section 3.

Currently, Mendel can only print with plastics, so work is being done to create new extruder heads that can print other materials. Developers are currently working on a paste extruder as it can be used many materials (Sells, et al., 2009), a spoolhead extruder to print metal wire onto plastic which in future can be used to print circuit boards (Bayless, Chen, \& Dai, 2010), and a granule extruder including a method to create the granules (Braanker et al., 2010; Tan and Nixon, 2007). A granular extruder is particularly relevant to OSAT related printing involving the use of locally sourced materials. A new extruder mount has been developed to pick up and place plastic components together and an inkjet printer for the RepRap has been made (Jaipuria, 2010). Work is in progress to use a RepRap with a laser cutter head, scribing tool head, a photopolymerization head and a selective laser sintering extruder head (RepRap, 2010). All these different extruder heads will help RepRap gain full replication and greater OSAT component potential.

There are several current limitations with the RepRap, the largest being its printing time. Currently, the deposition occurs at around $15 \mathrm{~cm}^{3} / \mathrm{hr}$ which would make the production of large parts prohibitively slow (RepRap, 2010), though a slightly modified RapMan machine has printed up to 5 times faster (Wolschon, 2010). In addition, the durability of the machine has yet to be proven in long-term real-world testing, however it is hopeful that a large portion of the machine can be printed, and therefore replaced when parts wear out. The machine has a $0.5 \mathrm{~mm}$ diameter nozzle and has $0.1 \mathrm{~mm}$ positioning accuracy and 0.3 layer thickness (RepRap, 2010). The tolerances for the machine are acceptable for many consumer grade products and OSAT related components.

\subsection{Fab@home}

The Fab@home printer, which was designed at Cornell University by Hod Lipson and Evan Malone, costs $\sim$ 2,300 to construct, including laser cutting acrylic parts (Malone and Lipson, 2007; Fab@home, 2010). The Fab@home, much like the RepRap, uses a three axis system driven by stepper motors and uses extruded layers of working material to build up the 3-D shape (Malone \& Lipson, 2007). The Fab@home, however, uses a syringe based extruder that currently allows for many more materials than the RepRap as seen in Table 1. Currently it can print with anything that is a liquid or paste including already tested: silver ink/paste, silicone rubber caulk, epoxy, cheese, cake frosting, ceramic clay (mixed with ample water), PlayDoh, gypsum plaster, chocolate, WindowArt, and Crayola's squeezable paint (Chung, et al., 2008; Fab@home, 2010; Kraftmark, 2008; Malone \& Lipson, 2006). It is clear that most of the standard printing materials for the Fab@home are not particularly useful for OSAT applications. In addition, various hydrogels, used to print scaffolding for cell growth, have also been explored (Cohen, et al., 2006; Skardal, et al., 2010). A printer head has also been developed to use granules of working material instead of the normal paste compounds (Tan \& Nixon, 2007) and one that prints ice sculptures using a valve nozzle deposition system, which may be useful for fabricating support for more complex objects and overhangs (Barnett, et al., 2009). Finally, a plastic extruding head and metal extruding head have been developed, which feed strands of material into the extruder that are heated up and deposited, much like the RepRap (Malone, et al., 2008). The printed object size for Fab@home is significantly smaller $\left(8 \mathrm{in}^{3}\right.$ or $\left.131 \mathrm{~cm}^{3}\right)$ than RepRap, and there has been no concentrated effort to make this machine able to print itself, as the pieces that make up the machine are generally much larger then the machine's printable area (Fab@home, 2010). This severely restricts the use of the Fab@home for OSAT applications.

The Fab@home can print with multiple materials in a single printed object although the materials can not be deposited simultaneously. When printing with multiple materials, the more important part is printed first and the 
less important part (in the other material) is printed into the original part. This process involves an extruder head change for the different materials. Using this technique the following devices have been printed: zinc-air battery (Malone, et al., 2008), u-shaped battery that contains two cells, electromagnet, strain-gage and flashlight with placed in components (Malone and Lipson, 2008), custom circuit board (Periard, Malone, \& Lipson, 2007), actuator (Malone \& Lipson 2006), partially printing an electromechanical relay (Malone \& Lipson, 2007a), electrochemical transistors on a glass substrate (Boyea, Malone, \& Lipson, 2008), and organic electrochemical transistors printed on a glass substrate (Havener, et al., 2007). These components may be useful for more advanced local production of OSAT.

The Fab@home has some faults. The nozzle, like the RepRap, must be set up at a very specific height and extrude at very specific speed for good prints. This calibration involves thorough testing as the correct speed and height varies between machines. The accuracy of the objects printed by the machine generally depends on the material that is used. With a good working material the $x-y$ resolution is about twice the nozzle diameter, while $z$ resolution is about the nozzle diameter. In terms of positioning, the Fab@home is within -/+ 25 micrometers and has a repeatability of -/+ 100 micrometers (Fab@home, 2010). The nozzles can deposit material in paths 250-1500 micrometers in diameter depending on the property of the deposition material (Malone \& Lipson, 2008). Although the print size limits Fab@Home's ability to be used to print OSAT, the ability to print various materials could be combined with RepRap to expand the printable OSAT. Finally, it should be noted that although Fab@home has a BSD license and the firmware is FOSS, it is windows-centered. The software, FabStudio is currently only compatible with the Windows operating systems due to its reliance on MFC version 8.0. This also mandates the use of the full version of visual studio 2008 in order to edit and compile the source code (Lipton, 2010). These proprietary software packages radically increase the costs of the 3-D printer package. The reliance on proprietary and expensive software severely restricts the scaling of this technology to help the spread of OSAT in the developing world.

\subsection{Designs for 3-D Printers}

The items to be printed on the RepRap and Fab@home must be drawn in a 3-D CAD program, and subsequently converted to a .STL file, which can be done through free, open-source software (Sells, et al., 2009; Malone \& Lipson, 2007). There are a variety of open source and free 3-D CAD programs available such as Blender, Art of Illusion, OpenSCAD, and BRL-CAD (a partial list is available http://www.appropedia.org/Open_source_engineering_software). In addition, there is currently an online exchange of free models for 3-D printing, located at www.thingiverse.com run by Makerbot Industries. At the moment, the site focuses largely on novelty or test pieces for a 3-D printer, but provides a repository and/or a model for a possible OSAT online exchange, which would support the OSAT community. The makers of Fab@home have also started an educational website, www.3dprintables.org, that houses education models from recreations of gear sets to manifolds and folded proteins to be printed on rapid prototypers including some basic engineering specifications. Further technical information about the parts would clearly assist designers modify parts for OSAT applications, and should be included in an OSAT exchange database. Despite these databases, there is still a need for product designers who know how to create the necessary CAD files and make modifications to existing files, to suit personal needs and maximize usability of 3-D printers.

\section{Potential Applications of Local 3-D Printing to OSAT}

Open source 3-D printers, which are priced in a region that are accessible to most college students provides for the first time the sharing of engineering drawings to allow open design to assist at scale in sustainable development. Previously, the closest ability to scale was through Fab Labs that provide widespread access to modern means for invention and which enabled members of a community to make a functional machine shop with high-tech modern equipment for fabricating technologies such as bicycles in their local communities (Mikhak, et al., 2002). These machine shops enable local innovation and design. However, the Fab Lab machines still require experts to operate them (Mikhak, et al., 2002). The modern 3-D printer differs from this as it is a true $\mathrm{CNC}$ printer capable of producing open designs to spec with no skilled machining necessary.

The applications of the home 3-D printer are endless and there is already speculation that it will be used in the industrialized world as a means for uber-customization for luxury items (Bernard \& Fischer, 2002). In the context of sustainable development the printers can enable low cost production of OSAT customized to local needs. Since designs can be produced and modified locally using a computer, computer programs can also be written to produce designs optimized for user input (e.g. a prosthesis based on arm length). 3-D printing access could enable technologies, which previously were not considered to be AT (due to the non-availability of replacement parts or resources to maintain them), to become sustainable by the local communities. In this way, the use and availability of 3-D printers builds local capacity (Murphy, McBean, \& Farahbakhsh, 2009) and participation (Faillace, 1990) necessary for successful AT implementation (Buitenhuis, Zelenika, \& Pearce, 2010), while simultaneously allowing the communities to fully access and use the resources potential of open-source development. This local design and innovation can then be scaled globally and used by people in other communities to meet their own needs, on a similar trajectory to that laid out for Fab Labs (Mikhak, et al., 2002). An open-source printer would be an outlet and a reason for having high-tech CAD and design skills. It 
would encourage training and provide meaningful sustainable employment in which skilled workers could give back to their community, becoming product designers or technical support experts for the printers.

3-D printed OSAT parts have broad uses, but are currently restricted by the printing abilities of open-source 3D printers. The printed parts can be useful across many industries, not limited to energy and fuels, to farming, water or food production and storage, medical devices, transportation, handicrafts, housing, and industrial applications. As follows from Section 2 of this paper, 3-D printing is most applicable to components that are i) small, ii) highly customizable, iii) expensive to manufacture/ship, iv) difficult to transport, v) have a large lead time, vi) do not require precise machining and can handle small imperfections, and vii) can be made from available, cheap, and technically viable feed stocks.

For the purpose of discussing OSATs to be developed by open source 3-D printing, they can be grouped into the following four broad classes:

Class 1. Current: Technically able to be printed on current printers, using viable tested materials, and economically advantageous over other means of production; these are primarily mechanical parts, which can be built from plastic and are not subject to large breaking forces or extreme temperatures. These components will be economically advantageous to build if the cost to import them is significant, which would be primarily due to transportation and middle-men markup costs.

Class 2. New Materials: Technically able to be printed on current printers, but not using viable tested materials, and economically advantageous over other means of production. These parts require either casting or further development of extruders.

Class 3. Larger Printers: Technically able to be printed on printers if the size were expanded, using viable tested materials, and economically advantageous over other means of production. These parts require further development of printing head drivers.

Class 4. Larger Printers and New Materials: Technically able to be printed on printers if size of printer were expanded, but not using viable tested materials, and economically advantageous over other means of production.

The term 'technically able to be printed on current printers' refers to the ability to meet material property, accuracy, size and resolution requirements of the printed part and that the overhangs necessary to print the part are manageable.

Examples of Class 1 objects are facial prosthetics, which using 3-D printing are already being investigated for the developed world (Feng, et al., 2010) and limb prostheses. Prostheses are typically very expensive, and widespread issues with availability and distribution (Beshai \& Bryant, 2003) causes poor access in developing countries (Borg, 2009). Less expensive designs, such as the Niagara Foot (Gabourie, 2010), are being tested in the developing world already. Creating prostheses locally with a 3-D printer would allow local customization and cut down on transportation costs. To develop OSAT 3-D printed prostheses further, testing must be done on the breaking strengths and failure modes of 3-D printed objects with feedstock able to be obtained in developing countries. A second group of examples for Class 1, would include parts of systems, which would require additional pieces produced elsewhere to be used such as water system parts. Among other challenges to AT water systems, pumps frequently fail (Short, 2003) and the availability of spare parts is low. Simple parts, which could be printed, like taps that are a leading failure mode (Meah, Ula, \& Barrett, 2008). Tools and parts could be produced, or existing tools could be customized for greater productivity (Rogan \& O'neill, 1993; Roman \& Holtslag, 1995), including lightweight wrenches; low force mating gears; hinges; clamps with gearing systems; low force buckles and snaps for easy assembly/dis-assembly of mating parts; and pulleys.

A Class 2 components' shape can be built using a 3-D printer in plastic, but must be cast into a different material to provide the mechanical attributes required of the final product following the scheme outlined by Open Source Ecology (2010). These items operate in high temperatures where plastic would deform; or they require strength greater than plastic could provide. Items could be designed and prototyped on a 3-D printer in plastic, and then used as a mold for metal casting, within the constraints of metal casting fabrication (Sabberwal, 1981; Karunakaran, et al., 2010). The benefit of creating the plastic as a mold allows complex and cheap design iterations in plastic, conserving resources where metal is in short supply (Sabberwal, 1981). The accuracy in parts can be improved before final pouring of the mold by deburring of the plastic and making alterations to the plastic models. Another option is to print OSAT directly in different materials that are appropriate for their use, which requires further advances in materials printing abilities. Examples of a Class 2 OSAT include stove components such as grills (Brattle \& Irving, 1986) and electrical circuit boards which can enable a broad range of technologies. Although it should be stressed here that forged objects are stronger than poured ones (Hurst, 1996) there is a potential to fabricate a number of mechanical parts. It should also be noted here, that although there are experimental printers developed that are not limited to plastics, there has been very little reliability testing with other materials, and these printers can not yet be considered available.

Class 3 objects are parts that can be built in larger pieces of plastic, in applications where high strength is not required, and the environment is not extremely hot or cold. For 3-D printers to be effective at producing such pieces, the print speeds for these large parts must drastically increase. The strength of very large objects has to be 
especially noted, as materials that could provide sufficient strength for the small stresses applied to smaller objects may not be sufficient to withstand large stresses on large objects. For example in construction during the Renaissance, the miniature models appeared to be structurally sound, but the full scale buildings often collapsed. Examples of a Class 3 AT are solar dehydrators (Dahlman \& Forst, 2001), solar stills (Pearce \& Denkenberger, 2006; Khanna, et al., 2008), and solar pasteurizers (Denkenberger \& Pearce, 2006).

Class 4 represents large products that cannot be manufactured in plastic due to specified material properties. These items can be printed first in plastic and molded, or printed directly in a different material with advances in the printing technology, as mentioned in Section 2. Such techniques would be useful to make a Class 4 object such as a large locking pressure cooker for desalination (Buros, 2000), as the detailed mechanical design required to have it seal could easily be produced in plastic and then molded to resist the heat and pressure. Other examples of Class 4 objects are large farm and industrial equipment and bulky medical equipment.

\section{Necessary Research in 3-D Printing of OSAT}

As outlined in Sections 2 and 3, it is clear that the technology of OSAT 3-D printing is far from its evolutionary climax. For OSAT applications, the ideal functional requirements of a 3-D printer include:

-Inexpensive machine ideally self-replicated and fabricated with locally available materials

-Inexpensive feedstocks with locally available materials

-Free and open access to designs, and designing software

-Inexpensive and rapidly fabricated parts

-Low energy use and powered by locally available renewable energy resources (e.g. solar photovoltaic cells)

-Open/freely available technical support and knowledge

-Socially acceptable use patterns

-Minimal negative health, social and environmental effects of use or construction of the 3-D printer

A printer which satisfies these conditions coupled with a CAD-enabled computer such as the OLPC, a few simple tools (such as files), a power source, and any machinery required to generate feedstocks from local resources can be an independent production facility, and provide complete village-level fabrication of OSATs. In addition, in OSAT applications, post-processing is tolerable (de-burring, etc.) so the properties and tolerances for specific parts can be relaxed from commercial rapid prototyping as long as they are suitable for specific AT applications. Combining these requirements with the information from Section 3, it is clear that the following key additional technical barriers need to be overcome to make 3-D printing a viable technique for OSAT deployment: 1) development of locally available materials for printing, 2) the size of printed object and print speed need to be increased, 3) an increased and improved material selection for 3-D printing is necessary, and 4) the development of a solar powered 3-D printer/computer for deployment in rural developing communities.

\subsection{Local Materials}

It is critical that feed stocks be developed from locally-available materials in order to prevent the erosion of cost advantages for local production. Using locally-available materials for fabricating OSAT not only ensures the community in question will be less dependent on foreign assistance if there are problems with the technology, which currently is a frequent occurrence (RepRap, 2010; Fab@home 2010), but it also creates a sense of empowerment as technology is not handed out as a form of charity furthering dependence on foreign aid (Gellerman, et al., 2009). This can be accomplished through the use of feedstocks created from waste products (e.g. plastic bags) or through the use of available local materials such as bio-polymers. The sheer abundance of plastics in household waste (including bags, bottles, food and entertainment packaging) is a reality in most non-rural communities (Al-Khatib, et al., 2010; Phillipe \& Culot, 2009), but this waste can be reused. An example of such an application is the project Waste for Life, which resulted in a partnership with local communities whose daily existence depends on collecting paper, plastics and other seemingly invaluable trash (Baillie, 2008). Waste for Life has developed an open source hotpress (compression moulder) which is used to turn trash consisting of plastic bags and cardboard pulp into valuable composites (Matovic, 2010). A similar process could be used to create a bio-composite filament for use in the RepRap. Thus a plastic extruder, which could heat the plastics and extrude them as a filament that can be used by the 3-D printer, is necessary. It should be noted that producing filament feedstock is a challenge as the diameter has to be precise and the filament must be very round (not oval) or the extruder will produce poor quality parts or jam as has been often encountered when RapMan owners buy replacement filament locally. A hopper-designed extruder may not be as dependent on the size properties of the material and also reliable advances in using pellet feed stock combined with a pelletizer is another option (Braanker, et al., 2010).

The development of new printer heads, which can print in metal would also greatly expands the utility of 3-D printers to fabricate AT. The ability to incorporate recycled metals into printed items would allow for the printing of mechanically reinforced objects as well as switches and other electrically conductive applications. An 
important issue to keep in mind is that not every community will have an equal access to particular materials, and the amount of different waste products in garbage varies widely, even between different cities (Al-Khatib, et al., 2010; Phillipe \& Culot, 2009). There may be an even bigger divide between city and rural areas, as for example, communities in Bogota might have an abundance of discarded plastics readily available for their application as feedstock materials, while more isolated communities might not. As such it is important to diversify the feedstock material options as much as possible and to design and build the 3-D printers to be versatile and able to adapt to the local needs of the community. Once again the fastest and easiest way to facilitate such versatility is through some form of open source collaborative design (Buitenhuis, Zelenika, \& Pearce, 2010).

\subsection{Larger Faster 3-D Printers}

Although more complex and large objects can be fabricated with an existing small scale 3-D printer by breaking pieces into smaller components and using mechanical or chemical means of fusing them into larger objects, larger printers are needed to fabricate objects that can take advantage of the reduced energy and costs of transportation for large and/or heavy objects, such as housing and large industrial materials (Harrison \& Sinha, 1995; Keivani \& Werna, 2001). Some applications of large 3-D printers can be found for housing projects, modeling large equipment, bulkier medical equipment, transportation containers, and even using products from the printer for education purposes. Large 3-D printers can also help conceptualize many technical concepts that are often only addressed theoretically or abstractly in many universities (Lipson, 2007). In addition, improvements in the printer's speed would allow these large pieces to be printed in a more reasonable time. These improvements could come from printing in different materials, or a different machine design. Work is already being done that could be drawn upon with concrete printers or 'contour crafting' that could even be used to print entire houses out of locally available construction materials (Khoshnevis, 1998; Khoshnevis, et al., 2001; Buswell, et al., 2008). If large 3-D printing technology is coupled with OSAT it is clear that it could provide a means to reduce costs for high-quality shelter, one of the necessities for sustainable development.

\subsection{Better Feed Stocks and Casting}

As open source 3-D printing is largely relegated to the hacking community, the full weight of the materials science and engineering community has been yet been applied. When the materials and accuracies developed for open source 3-D printing listed in Table 1 and 2 are compared to commercial 3-D printer's properties (Noorani, 2006), the mechanical properties are equal or superior for the open source 3-D printer. For example when comparing RepRap to selective laser sintering (SLS) techniques, which fuse powder, there is a clear advantage in Izod impact tests for RepRap, with SLS parts achieving less than half of most of RepRap's capable materials (Noorani, 2006). However, there is a much larger range of materials available with commercial rapid prototyping machines, such as metals, ceramics, photopolymers, and composites, and advanced construction techniques allow commercial rapid protytyped parts have a much higher accuracy, up to $0.025 \mathrm{~mm}$ (Noorani, 2006). Development of materials and construction processes which could be printed on open-source 3-D printers with a comparable accuracy, and expansion of the available feed stocks to include high-temperature ceramics would enable production of a much broader range of technologies, customized to local needs. Casting methods using plastics and techniques that would be available in developing countries (Hurst, 1996) can also be researched instead of directly printing in different materials. In this way, mechanical properties of all finished objects could be improved.

\subsection{Solar powered 3-D printer/computer for deployment in rural developing communities}

About a quarter of the global population have no access to electricity and $80 \%$ of these people live in rural areas of the developing world, mainly in South Asia and sub-Saharan Africa (IEA, 2005). In order for rural communities to have access to the benefits of open source 3-D printing they will need electric power from locally available renewable resources. Solar photovoltaic technology, which converts sunlight directly into electricity, is a technically viable, environmentally benign, and increasingly economical method of providing electricity to both on grid and remote communities all over the world (Pearce, 2002; Yang, 2010). Solar photovoltaic electricity conversion is particularly well suited for small scale off-grid applications because the power draw on a small laptop computer such as the OLPC and the RepRap is $<100 \mathrm{~W}$, which is well within the range of commercialized photovoltaic systems. By using distributed solar electricity the costs associated with extending the grid are avoided. In order to take advantage of this opportunity, a small battery and photovoltaic charging system appropriate for powering the laptop and the open source 3-D printer needs to be designed and tested.

\section{Discussion}

The research required to develop open source 3-D printers to the point where they can be used reliably for AT is non-trivial and is a barrier to this OSAT's success. As reviewed here, open source 3-D printing is currently in the hacker/development stage and does not have the reliability nor the testing and verification needed to deploy in the field in developing countries. The development of the open source 3-D printer for OSAT should not follow the historic models of other AT, as the majority of AT research has been accomplished by time-consuming trial 
and error methods in the field by individuals without technical backgrounds. The open source collaborative method, developed by the software community is a useful model and something that is already underway in the development of the RepRap and the Fab@home. This open collaboration can be further enhanced by 1) using it to better characterize printed AT parts and to perform a suitability analysis for a given application and 2) leveraging engineering service learning to provide some of the development.

First, for the further development of open source 3-D printers for OSAT, it is important to develop a more rigorous method for testing the printed parts. Analysis of parts would ideally occur in an analytical machine designed for failure mode analysis, using devices such as strain meters and vibration tests, but could also be achieved with simple weight-testing of strength (Pfeifer, 2009) in remote communities. The following properties of 3-D printed items can be tracked and posted openly in an online database along with the CAD designs: i) print accuracy obtained; ii) electricity consumed, iii) time to print; iv) quantity of materials required for production; and v) mechanical properties including: strength of part (bending, breaking), yield stress (both tensile and shear), elastic limit, elastic modulus, Poisson's ratio, stress (F/A), and hardness. The accuracy can be determined with the use of a caliper. The electricity used can be measured with inexpensive power meters, the materials used determined by measuring the length of the feedstock consumed, and the time simply noted or recorded during printing. These will capture the whole deposition process in quantitative measurements that can be compared across projects. A standardized strength property could be obtained for each printer and material by printing an I-beam and testing deformation properties and failure modes following standard testing protocols. Making these results publicly available through the open-source methodology can help to encourage developments and use of the printer for applications, as these results can then be compared to the requirements of any proposed object.

Once the mechanical capabilities of 3-D printed parts are documented, the following method may be employed to evaluate the suitability of 3-D printing to create proposed objects, both theoretically and through testing: i) calculate expected forces on proposed objects through momentum or speed change calculations, or finite element analysis modeling; ii) find typical breaking strengths of similar objects through the mechanical properties of the standard manufacturing material to obtain an estimate of the strength required in the proposed object; iii) find typical tolerances required through manufacturers of similar objects; iv) determine typical use conditions (i.e. temperature and wear); v) compare economics of producing the part with the 3-D printer against other locally available production methods and shipping + markup + purchase costs of having it made elsewhere; vi) and finally consider the social and environmental impact of manufacturing the part with a 3-D printer against other means or not at all. Recording results of both part-testing and suitability analysis in a structured and easily transferable and understandable, standard way would allow full use of the global OSAT community.

This level of development work on the potentially thousands of appropriate technologies, which may be viable candidates for 3-D printing represents an enormous task; much larger than that which could be expected in the next several years from the open source 3-D printing community. Fortunately, there is an increasing use of service learning to produce OSAT (Pearce, 2007), which could be used as a model for the integration of open source 3-D printing into the OSAT community. Recently developed OSAT-focused internet tools can enable this process. In particular, the wiki Appropedia has been used for service learning support (Pearce, et al. 2008; Pearce, 2009) and is particularly well suited as a model. Recent examples of OSAT development in classrooms include: water filtration systems (Heil, et al., 2010), wind powered LED lighting (Thomas, 2007), and AT wheelchairs (Winter, 2006). The operations of most ATs are governed by physical laws taught in introductory physics and engineering classes, which make the technological development accessible to the students. In addition, the technical development and suitability analysis of both printed designs and the 3-D printer itself would easily find application in many university-level engineering courses. Students have access to the scientific literature in the university libraries, relatively sophisticated scientific equipment (e.g. computer-integrated thermocouples), and fully equipped machine shops (that can be used to both prototype and RepStrap: build the parts to make a RepRap). Finally, most engineering students have access to very sophisticated design and simulation software tools - such as Solid Works and Solid Edge for 3-D CAD design of OSAT to be printed on 3-D printers. However, it should be noted that in order for local populations to have the best access to the designs, open source engineering software should be used and further developed. Finally, with the current costs of 3-D printers being within the range of equipment for most undergraduate science and engineering labs it is clear that OSAT development for 3-D printing is within the scope of most universities abilities. By helping to develop OSAT for 3-D printing students can perform the basic research necessary to optimize such devices, while gaining a better understanding of physical principles and engineering practice.

Future work is needed to explore three important aspects of using the RepRap or other 3-D printer for OSAT: 1) A full analysis of, and possible avenues of obtaining, the required resources (time, money, materials, knowledge) to actually start up, and then run a small scale 3D-printing OSAT production facility in rural areas is needed. The materials part of the equation would be partially satisfied by a proof of concept operation of a RepRap controlled by an OLPC and powered with a solar photovoltaic system.

2) Full testing of the present abilities of open source 3-D printed parts is needed, including testing a structural part to failure to determine general properties; and analysis/development of necessary testing equipment which 
could be available to open source 3-D printer users in the field, in order to contribute numerically to the knowledge base on printed OSAT. This can be accomplished by printing a series of beams of different materials, testing them and reporting the results to the open source community.

3) There are social requirements for the success of 3D-printed OSAT deployment that should be addressed if a scalable and repeatable village-level OSAT fab is going to be a success. For example, it will probably be necessary to enable local training and knowledge transfer (both technical/social). A business case will need to be made for the project and local demand for printed AT will need to be quantified. In addition, both the requirements for local leadership of the project and leaders will need to be identified for each community. Research into meeting such social requirements may lead to further technical requirements and improvements.

\section{Conclusions}

This study reviewed the present capabilities of the two leading open source 3-D printers, the RepRap and the Fab@home, with particular focus on their applicability to developing appropriate technology for sustainable development. It found that open source 3-D printing is currently in the hacker/development stage and does not have the reliability nor the testing and verification needed to deploy in the field in developing countries. A new classification scheme was presented to determine the OSAT applications that are technically feasible and economically viable for production at projected stages of open source 3-D printer development. Research trajectories were outlined to improve local feed stock availability, size of printed parts, material properties, and the use of renewable energy systems to extend the existing 3-D printing technology to provide complete village-level fabrication of OSATs. A more rigorous method for quantifying the properties of the printed parts is proposed along with a methodology to evaluate the suitability of 3-D printing to create proposed objects. Finally an open source development model is discussed, which can benefit from engineering service learning. Given appropriate resources, there is clearly enormous potential for open source 3-D printers to assist in driving sustainable development for all of the world's people.

\section{References}

Al-Khatib, I. A., Monou, M., Abu Zahra, A. S. F., Shaheen, H. Q., \& Kassinos, D. (2010). Solid waste characterization, quantification and management practices in developing countries. A case study: Nablus district - Palestine. Journal of Environmental Management, 91(5), 1131-1138.

Baillie, C. (2008). Waste for Life. Student learning through international development projects. Who pays and who benefits? Materials Today. 11(10), 6 .

Barnett, E., Angeles, J., Pasini, D., \& Sijpkes, P. (2009). Robot-assisted rapid prototyping for ice sculptures. Proceedings of the 2009 IEEE International Conference on Robotics and Automation, Kobe, Japan, 871-876.

Bayless, J., Chen, M., \& Dai, B. (2010). Wire embedding 3D printer, University of British Columbia, Vancouver, BC. [Online] Available: http://reprap.org/mediawiki/images/2/25/SpoolHead_FinalReport.pdf (July 23, 2010).

Bernard, A., \& Fischer, A. (2002). New Trends in rapid product development. CIRP Annals - Manufacturing Technology, 51(2), 635-652.

Beshai, M. \& Bryant, T. (2003). Victim assistance efforts: The Niagara foot. Journal of Mine Action, 7(1). [Online] Available: http://www.maic.jmu.edu/Journal/7.1/notes/beshai/beshai.htm?ref=casinobettingaction.info (June 22, 2010)

Borg, J., Lindström, A., \& Larsson, S. (2009). Assistive technology in developing countries: national and international responsibilities to implement the Convention on the Rights of Persons with Disabilities. The Lancet, 374(9704), 1863-1865.

Boyea, J., Malone, E., \& Lipson, H. (2007). Electrochemical Transistors on Printed Substrates Patterned with Ink-Jet Printing. Ithaca: Cornell Center for Materials Research.

Braanker, G.B., Duwel, J.E.P., Flohil, J.J., \& Tokaya, G.E. (2010). Developing a plastics recycling add-on for RepRap 3D Printer. [Online] Available: http://reprapdelft.files.wordpress.com/2010/04/reprap-granule-extruder-tudelft1.pdf (June 30, 2010).

Brattle, L. V., \& Irving, R. J. (1986). Appropriate household technology: charcoal stoves. Journal of Consumer Studies \& Home Economics, 10(1), 35-43.

Buitenhuis, A. J., Zelenika, I., \& Pearce, J. M. (2010). Open Design-Based Strategies to Enhance Appropriate Technology Development. Proceedings of the $14^{\text {th }}$ Annual National Collegiate Inventors and Innovators Alliance Conference : Open, March 25-27 $7^{\text {th }}$ 2010, pp. 1-12. Available: http://nciia.org/sites/default/files/pearce.pdf

Buros, O.K. (2000). The ABCs of desalting (2nd ed.). Topsfield: International Desalination Association.

Buswell, R.A., Thorpe, A., Soar, R.C., \& Gibb, A.G.F. (2008). Design, data and process issues for mega-scale rapid manufacturing machines used for construction. Automation in Construction, 17(8), 923-929.

Cheah, C. M., Nee, A. Y. C., Fuh, J. Y. H., Lu, L., Choo, Y. S., \& Miyazawa, T. (1997). Characteristics of photopolymeric material used in rapid prototypes Part I. Mechanical properties in the green state. Journal of 
Materials Processing Technology, 67(1-3), 41-45.

Chung, M., Malone, E., Tolley, M. T., Chepaitis , A. J.,\& Lipson, H. (2008). Object Augmentation for the Visually Impaired Using RP. Proceedings of the $19^{\text {th }}$ Solid Freeform Fabrication Symposium, Austin, Texas, United States of America.

Cohen, D. L., Malone, E., Lipson, H., \& Bonassar, L. J. (2006). Direct freeform fabrication of seeded hydrogels in arbitrary geometries. Tissue Engineering, 12(5), 1325-1335.

Dahlman, J., \& Forst, C. (2001). The solar dehydrator. In Technologies demonstrated at ECHO. North Fort Myers: ECHO.

Denkenberger, D.C. \& Pearce, J.M. (2006). Compound Parabolic Concentrators for Solar Water Heat Pasteurization: Numerical Simulation. Proceedings of the 2006 International Conference of Solar Cooking and Food Processing, 108

Fab@home. (2010). Fab@home the open source personal fabricator project, Frequently Asked Questions [Online] Available: http://fabathomebeta.mae.cornell.edu/?q=faq (June 23, 2010).

Faillace, C. (1990). The importance of using simple and indigenous technologies for the exploitation of water resources in rural areas of developing countries. Journal of African Earth Sciences, 11(1-2), 217-220.

Feng, Z., Dong, Y., Zhao, Y., Bai, S., Zhou, B., Bi, Y., \& Wu, G. (2010). Computer-assisted technique for the design and manufacture of realistic facial prostheses. British Journal of Oral and Maxillofacial Surgery, 48(2), 105-109.

Ferreira, F.H.G. \& Ravallion, M. (2008). Global Poverty and Inequality: A Review of the Evidence. World Bank Policy Research Working Paper No. 4623.

Gabourie, R. (2010). Niagara Foot Update. Niagara Prosthetics \& Orthotics International Ltd [Online] Available: http://www.niagarafoot.com/pdf/NiagaraFoot_UpdateMay2010.pdf (June 22, 2010).

Gellermann, J. P., Brennan, M., Nirmul, D., \& Lenfesty, K. (2009). Understanding Sustainability: The Importance of Sustainable Development and Comprehensive Planning. University of Florida IFAS Extension. [Online] Available: http://edis.ifas.ufl.edu/fy1104 (June 22, 2010).

Harper, C. (2001). Handbook of materials for product design (3rd ed.). New York: McGraw-Hill, (Chapter 4).

Harrison, S. W. \& Sinha, B. P. (1995). A study of alternative building materials and technologies for housing in Bangalore, India. Construction and Building Materials, 9(4), 211-217.

Havener, R., Boyea, J., Malone, E., Bernards, D., DeFranco, J., Malliaras, G., \& Lipson, H. (2007). Freeform fabrication of organic electrochemical transistors. Proceedings of the 18th Solid Freeform Fabrication Symposium, Austin, Texas, United States of America.

Hazeltine, B. \& Bull, C. (Eds.) (2003). Field Guide to Appropriate Technology. San Diego: Elsevier Science.

Heil, E., Nengwenani, D., Raedani, A., Gutierrez, V., Nthambeleni, G., Mathoma, K., Brown-Glazner, R., \& Swap, R. (2010). Student-led, Community Driven Improvement of the Drinking Supply in a Rural Village in South Africa. International Journal For Service Learning In Engineering, 5(1), 94-110.

Hurst, S. (1996). Metal Casting: Appropriate Technology in the Small Foundry. London: Intermediate Technology Publications.

IEA. (2005). The Developing World and the Electricity Challenge. [Online] Available: http://www.iea.org/Textbase/work/2005/poverty/blurb.pdf. (July 23, 2010)

Japuria, A. (2010). Inkjet Printer for the RepRap. [Online] Available: http://reprap.org/mediawiki/images/1/1a/Inkjet.pdf (June 29, 2010).

Kanter, A. S., Negin, J., Olayo, B., Bukachi, F., Johnson, E., \& Sachs, S. E. (2009). Millennium global village-net: Bringing together Millennium Villages throughout sub-Saharan Africa. International Journal of Medical Informatics, 78(12), 802-807.

Karunakaran, K.P., Suryakumar, S., Pushpa, V., \& Akula, S. (2010). Low cost integration of additive and subtractive processes for hybrid layered manufacturing. Robotics and Computer-Integrated Manufacturing, 26(5), 490-499.

Keivani, R. \& Werna, E. (2001). Modes of housing provision in developing countries. Progress in Planning, 55(2), 65-118.

Khanna, R.. K., Rathore, R.S., \& Sharma, C. (2008). Solar still an appropriate technology for potable water need of remote villages of desert state of India - Rajasthan. Desalination, 220(1-3), 645-653.

Khoshnevis, B. (1998). Innovative rapid prototyping process makes large sized, smooth surfaced complex shapes in a wide variety of materials. Materials Technology, 13(2), 52-63.

Khoshnevis, B., Bukkapatnam, S., Kwon, H., \& Saito, J., (2001). Experimental Investigation of Contour Crafting using Ceramics Materials. Rapid Prototyping, 7(1), 32-41. 
Kipp, D. (Ed.). (2004). Plastic material data sheets. Blacksburg: MatWeb, Division of Automation Creation, Inc. Kraftmark Company. (2008). FabEpoxy Technical Data Sheet.[Online] Available: http://www.kraftmark.biz/pdfs/Fabepoxy/FabEpoxy.infosheet.pdf (July 5, 2010)

Li, C.L., Ya, K. M., \& Lam, T. W. (1998). Implementation and evaluation of thin-shell rapid prototype. Computers in Industry, 35(2), 185-193.

Lipson H. (2007). Printable 3D Models for Customized Hands-on Education. Paper presented at Mass Customization and Personalization (MCPC) 2007, Cambridge, Massachusetts, United States of America.

Lipton, J.I. (2010). Model 2 Software. Fab@Home Wiki. [Online] Available: http://www.fabathome.org/wiki/index.php/Model_2_Software. (July 23, 2010).

Matovic, D. (2010). Kingston Hot Press. [Online] Available: http://wasteforlife.org/wp-content/uploads/2010/02/Kingston-hotpress-documentation.pdf (July 13, 2010)

Malone, E., \& Lipson, H. (2006). Freeform fabrication of ionomeric polymer-metal composite actuators. Rapid Prototyping Journal, 12(5), 244-253.

Malone, E., \& Lipson, H. (2007a). Freeform fabrication of a complete electromechanical relay. Proceedings of the $18^{\text {th }}$ Solid Freeform Fabrication Symposium, Austin, Texas, United States of America, 2007, 513-526.

Malone, E., \& Lipson, H. (2007b). Fab@ Home: the personal desktop fabricator kit. Rapid Prototyping Journal, 13(4), 245-255.

Malone, E., \& Lipson, H. (2008). Multi-Material Freeform Fabrication of Active Systems. Proceedings of the ASME $20089^{\text {th }}$ Biennial Conference on Engineering Systems Design and Analysis, Haifa, Israel.

Malone, E., Rasa, K., Cohen, D., Isaacson, T., Lashley, H., \& Lipson, H. (2008). Freeform Fabrication of Zinc-Air Batteries and Electromechanical Assemblies. Rapid Prototyping Journal, 10(1), 58-69.

Meah, K., Ula, S., \& Barrett, S. (2008). Solar photovoltaic water pumping-opportunities and challenges. Renewable and Sustainable Energy Reviews, 12(4), 1162-1175.

Mikhak, B., Lyon, C., Gorton, T., Gershenfeld, N., McEnnis, C., \& Taylor, J. (2002). Fab Lab: An alternate model of ICT for development. Paper presented at the International Conference on Development by Design. Bangalore, India.

Murphy, H. M., McBean, E. A., \& Farahbakhsh, K. (2009). Appropriate technology - A comprehensive approach for water and sanitation in the developing world. Technology in Society, 31(2), 158-167.

Noorani, R. (2006). Rapid prototyping principles and applications. Hoboken, N.J.: John Wiley \& Sons, (Chapters 4,6).

Open Source Ecology. (2010). Open Source Fab Lab. [Online] Available: http://openfarmtech.org/index.php/Open_Source_Fab_Lab (July 23, 2010).

Pearce, J. (2002). Photovoltaics - A Path to Sustainable Futures, Futures, 34(7), 663-674, 2002.

Pearce, J. M. (2007). Teaching Physics Using Appropriate Technology Projects, The Physics Teacher, 45(3), 164-167.

Pearce, J. M. (2009). Appropedia as a Tool for Service Learning in Sustainable Development. Journal of Education for Sustainable Development, 3(1), 45-53.

Pearce, J.M. \& Denkenberger, D.C. (2006). Numerical Simulation of the Direct Application of Compound Parabolic Concentrators to a Single Effect Basin Solar Still. Proceedings of the 2006 International Conference of Solar Cooking and Food Processing, 118.

Pearce, J. M. \& Mushtaq, U. (2009). Overcoming Technical Constraints for Obtaining Sustainable Development with Open Source Appropriate Technology. Science and Technology for Humanity (TIC-STH), 2009 IEEE Toronto International Conference, Toronto, Ontario, Canada, 814-820.

Pearce, J. M., Grafman, L., Colledge, T. and Legg, R. (2008). Leveraging Information Technology, Social Entrepreneurship and Global Collaboration for Just Sustainable Development. Proceedings of the $12^{\text {th }}$ Annual National Collegiate Inventors and Innovators Alliance Conference, Dallas, Texas, United States of America, 201- 210.

Pfeifer, M. (2009). Materials enabled designs: The materials engineering perspective to product design and manufacturing. Boston: Elsevier.

Periard, D., Malone, E. \& Lipson, H. (2007). Printing Embedded Circuits. Proceedings of the $18^{\text {th }}$ Annual Solid Freeform Fabrication Symposium, Austin, Texas, United States of America: University of Texas, 503-512.

Philippe, F., \& Culot, M. (2009). Household solid waste generation and characteristics in Cape Haitian city, Republic of Haiti. Resources, Conservation and Recycling, 54(2), 73-78.

Pollock, P. (2009). Out of Poverty - What works when traditional approaches fail. San Francisco: Berrett-Koehler Publishers. 
Purdon, P. L., Millan, H., Fuller, P. L., \& Bonmassar, G. (2008). An open-source hardware and software system for acquisition and real-time processing of electrophysiology during high field MRI. Journal of Neuroscience Methods, 175(2), 165-186.

Pursell, C. (1993). The rise and fall of the appropriate technology movement in the United States, 1965-1985. Technology and Culture, 34(3), 629-637.

Rao, R. V., \& Padmanabhan, K. K. (2007). Rapid prototyping process selection using graph theory and matrix approach. Journal of Materials Processing Technology, 194(1-3), 81-88.

RepRap. (2010). RepRap. [Online] Available: http://reprap.org/wiki/Main_Page (June 30, 2010).

Rogan, A., \& O'Neill, D. (1993). Ergonomics aspects of crop production in tropical developing countries: a literature review. Applied Ergonomics, 24(6), 371-386.

Roman, L., \& Holtslag, H. (1995). The rope windpump. Energy for Sustainable Development, 1(6), 40-43.

Sabberwal, A. J. P. (1981). The Implementation of Appropriate Metal Working Technology in the Social Environment of the Developing Countries. CIRP Annals - Manufacturing Technology, 30(2), 571-575.

Schumacher, E.F. (1973). Small is beautiful: a study of economics as if people mattered. New York: Harper and Row.

Sells, E., Bailard, S., Smith, Z., Bowyer, A., \& Olliver, V. (2009). RepRap: The Replicating Rapid Prototyper-maximizing customizability by breeding the means of production. In F. T. Pillar \& M. M. Tseng (Eds.), Handbook of Research In Mass Customization and Personalization, Volume 1 : Strategies and Concepts. New Jersey: World Scientific. 568-580.

Short, T. \& Thompson, P. (2003). Breaking the mould: solar water pumping - the challenges and the reality. Solar Energy, 75(1), 1-9.

Skardal, A., Zhang, J., McCoard, L., Xu, X., Oottamasathien, S., \& Prestwich, G. D. (2010). Photocrosslinkable Hyaluronan-Gelatin Hydrogels for Two-Step Bioprinting. Tissue Engineering Part A, 100621062342080. [In-press] doi:10.1089/ten.tea.2009.079.

Tan, A., \& Nixon, T. (2007). Rapid Prototype Manufacturing System. Unpublished undergraduate paper, University of Adelaide, Adelaide, Australia.

Thomas, B. (2007). A Wind Powered, White LED Lighting System for the Kibera Slum of Nairobi. International Journal For Service Learning In Engineering, 2(1). 16-31.

Winter, V. A. G. (2006). Assessment of Wheelchair Technology in Tanzania. International Journal For Service Learning In Engineering, 1(2), 60-77.

Wolschon, M. (2010, May 1). Repman doing first $64 \mathrm{~mm} / \mathrm{s}$, then $86 \mathrm{~mm} / \mathrm{s}$. Bits From Bytes Forum. [Online] Available: http://www.bitsfrombytes.com/fora/user/index.php?topic=722.0 (July 23, 2010).

Yang, C. (2010). Reconsidering solar grid parity. Energy Policy, 38(7), 3270-3273. 
Table 1. Comparison of open source printers

\begin{tabular}{|c|c|c|}
\hline Characteristics & RepRap & Fab@home \\
\hline Ability to replicate & Yes, $\sim 50 \%$ & No \\
\hline Printable materials & $\begin{array}{l}\text { ABS, polycaprolactone, polyactic } \\
\text { acid, and HDPE }\end{array}$ & $\begin{array}{l}\text { Most pastes including: silicone rubber caulk, } \\
\text { epoxy, cheese, cake frosting, ceramic clay } \\
\text { (mixed with ample water), PlayDoh, gypsum } \\
\text { plaster, chocolate WindowArt, a product by } \\
\text { Klutz, GE black silicone, GE white silicon, } \\
\text { Crayola's squeezable paint, specially designed } \\
\text { conductive pastes, FabEpoxy and hydrogels }\end{array}$ \\
\hline Accuracy & $\begin{array}{l}0.5 \text { diameter nozzle } \\
0.1 \mathrm{~mm} \text { positioning accuracy }\end{array}$ & $\begin{array}{l}\mathrm{x}-\mathrm{y} \text { resolution is about twice the nozzle diameter } \\
\mathrm{z} \text { resolution is about nozzle diameter. } \\
\text { positioning is }-/+25 \text { micrometers off and } \\
\text { repeatability is around }-/+100 \text { micrometers. }\end{array}$ \\
\hline $\begin{array}{l}\text { Ability to print } \\
\text { electronics }\end{array}$ & $\begin{array}{l}\text { Not well developed, not solely done } \\
\text { by RepRap }\end{array}$ & Yes \\
\hline Printable object size & $1,110 \mathrm{~cm}^{3}$ or 67.7 inches $^{3}$ & $131 \mathrm{~cm}^{3}$ or 8 inches $^{3}$ \\
\hline $\begin{array}{l}\text { Alternate head } \\
\text { attachments }\end{array}$ & Granule extruder, Wax cutter, & $\begin{array}{l}\text { Ice printing head, granule head, metal printing } \\
\text { head, plastic printing head }\end{array}$ \\
\hline Cost of parts & $\$ 520$ (RepRap, 2010) & \$2400 (Fab@home, 2010) \\
\hline Deposition rate & $15 \mathrm{~cm}^{3} / \mathrm{hr}$ & Unknown, prints very small objects \\
\hline
\end{tabular}

Table 2. Properties of most common open-source printable materials (Kipp, 2004; Kraftmark, 2008)

\begin{tabular}{|c|c|c|c|c|c|c|}
\hline & $\begin{array}{c}\text { Typical } \\
\text { acrylonitrile- } \\
\text { butadiene-sty } \\
\text { rene (ABS) }\end{array}$ & $\begin{array}{c}\text { LARIPUR } \\
\text { LPR2102-85AE } \\
\text { (polycaprolactone) }\end{array}$ & $\begin{array}{c}\text { Ertalon } 6 \\
\text { PLA }\end{array}$ & $\begin{array}{c}\text { Typical } \\
\text { polyethylene } \\
\text { (HDPE) }\end{array}$ & Typical silicone & FabEpoxy \\
\hline $\begin{array}{l}\text { Tensile yield } \\
\text { strength } \\
\text { (MPa) }\end{array}$ & $13-50$ & 65 & 55 & $15-30$ & $1.2-5.5$ & $610 \mathrm{psi}$ \\
\hline $\begin{array}{l}\text { Tensile } \\
\text { modulus } \\
\text { (GPa) }\end{array}$ & $01 / 02 / 06$ & $0.01 \%$ & 1.7 & $\begin{array}{c}0.5-1.52 \\
\text { (flextural) }\end{array}$ & --- & --- \\
\hline $\begin{array}{l}\text { Elongation \% } \\
\text { at yield }\end{array}$ & $2-2.9 \%$ & $510.00 \%$ & $>50 \%$ & $260-875 \%$ & $200-600$ & $<6 \%$ \\
\hline $\begin{array}{l}\text { Izod impact, } \\
\text { notched } \\
(\mathrm{J} / \mathrm{cm})\end{array}$ & $0.48-2.4$ & --- & 7 & --- & --- & --- \\
\hline Hardness & $\begin{array}{c}68-115 \\
\text { (Rockwell) }\end{array}$ & 84 (Shore A) & --- & 58-65 (Shore D) & $18-40$ (Shore A) & 65 (Shore D) \\
\hline
\end{tabular}

